\title{
Time course of driving-skill self-assessments during French driver training
}

\author{
Vincent Boccara ${ }^{\mathrm{a}, *}$, Patricia Delhomme ${ }^{\mathrm{a}, *}$, Christine Vidal-Gomel $^{\mathrm{b}}$, Janine Rogalski ${ }^{\mathrm{b}}$ \\ a French National Institute for Transport and Safety Research, Laboratory of Driver Psychology, INRETS/LPC, 25 allée des Marronniers, Satory, F-78000 Versailles, France \\ ${ }^{\mathrm{b}}$ University of Paris 8, Department of Psychology, 2 rue de la Liberté, F-93200 St-Denis, France
}

Promoting self-assessment accuracy among student drivers could help improve the road safety for young novice drivers (Minimum Requirement for Driving Instructor Training, 2005). However, it is essential to first examine the time course of student drivers' assessments of their own driving skills. As a result, the present study examined the time course of student drivers' self-assessments in relation to their general driving abilities during the four steps of French driver training. We used Victoir et al.'s (2005) self-efficacy scale, which we translated into French. We set four goals for the present study: (1) to examine the psychometric qualities of this self-assessment scale, (2) to study the time courses of the students' self-assessments, (3) to investigate the relationship of these time courses to the number of driving hours that the students estimated that they needed to complete before taking the driving test, and (4) to compare the number of hours estimated by the students to the number of hours estimated by their driving instructors. In total, 150 students (58 men and 92 women) and 38 instructors from 13 driving schools in Paris participated in the present study. The self-assessment scale was composed of 12 items that were rated on a 7-point Likert scale that ranged from 1 (certainly so) to 7 (certainly not). The internal consistency of the scale was satisfactory $(\alpha=.88)$. The self-assessments became increasingly positive as the training progressed (at the beginning of training, $M=3.45$ vs. at the completion of the training, $M=4.8$ ). Globally, the men assessed themselves more positively than the women. However, no significant gender difference was observed at each training step. The students' self-ratings were negatively correlated with the number of driving hours that they estimated they still needed before taking the driving test. This number did not differ significantly from the number of hours that was estimated by the instructors at each training step throughout the training. The results describing the time course of the student drivers' self-assessments during driver training and this time course's correlation with the estimated number of driving hours still needed to take the driver test were discussed.

\section{Introduction}

In Organization for Economic Co-operation and Development (OECD) countries, $15-24$ year olds account for $18 \%$ to $30 \%$ of road deaths, whereas they represent between $9 \%$ and $13 \%$ of the total population (OECD, 2006). Death rates for young men are often three times as high as those for young women (Maycock, 2002; OECD, 2006). In France, road crashes were the number one cause of mortality for 15-24 year olds. In 2008, the death rates for young men who were 15-19 year olds were four times higher than those for women in the same age range and were six times higher for men who were $20-24$ year olds. ${ }^{1}$

\footnotetext{
* Corresponding authors.

E-mail addresses: boccara@inrets.fr (V. Boccara), delhomme@inrets.fr (P. Delhomme).

1 http://www.securiteroutiere.gouv.fr/IMG/pdf/2-SY_GDA_cle54e6da.pdf.
}

The fact that young novice drivers are over-confident is often presented as one of the causes of their over-representation in road crashes (OECD, 2006). Over-confidence in young drivers translates into an overestimation of one's driving skills and an underestimation of road risks (Delhomme, 1991; Delhomme and Meyer, 2004; Clarke et al., 2005b). According to the Goals of Driving Education (G.D.E.) model (Siegrist, 1999), promoting the development of student drivers' self-assessment skills could be a way to improve road safety for young novice drivers (Hatakka et al., 2002; Minimum Requirement for Driving Instructor Training, MERIT, 2005). Therefore, it is essential to first examine the time course of student drivers' assessments of their own driving skills. To our knowledge, no research has analyzed the development of drivers' self-assessments. The present study focused on the selfassessments of driving skills by students and the time course of these assessments during driver training but not on the accuracy of these self-assessments.

Drivers' assessments of their own driving skills are an important dimension of road risk management. Drivers, in general, tend to 
report that they avoid situations that they think they are less able to manage (Ball et al., 1998; Stalvey and Owsley, 2000; Lyman and Sims, 2001; Freund et al., 2005; Baldock et al., 2006). In contrast, drivers who have great confidence in their driving skills tend to drive at the upper limit of their driving skills (Matthews, 1986; Mckenna, 1993). Consequently, driving behavior can be related to the way individuals assess their own driving skills.

A common finding is that drivers tend to rate their own driving skills more positively than the "average driver" (Delhomme, 1991; OECD, 2006). Similarly, drivers rate their skills as higher with increasing in experience (Spolander, 1983; Lajunen and Summala, 1995). In addition, men assess their driving skills more positively than women do (Spolander, 1983; Delhomme, 1991; OECD, 2001; Engström et al., 2003; OECD, 2006), even when they are young novices (Gregersen, 1996; Delhomme and Meyer, 2004; Katila et al., 2004). This over-rating by young novice drivers increases during the first year of driving after licensing (Spolander, 1983). In contrast, Lajunen and Summala (1995) reported no significant effect of gender on young novice drivers' self-assessments. However, measuring drivers' ratings of how they compare to the "average driver" does not tell us whether the drivers overestimate their own driving skills (Sundström, 2008).

In contrast, driver training professionals might be the most capable people to provide an accurate assessment of drivers' skills because their job involves teaching those skills (Groeger and Clegg, 2007). Thus, assessments made by driver training professionals should be a good indicator of actual driving skills (studies about young drivers: Groeger, 2000; Groeger and Clegg, 2007; studies about senior drivers: Eby et al., 2003; Marottoli and Richardson, 1998). In their study, Mynttinen et al. (2009a, 2009b) compared driving-test candidates' assessments of their own driving skills to assessments made by driving examiners. The results of these studies showed that approximately $30 \%$ of the Finnish candidates, approximately $40 \%$ of the Dutch candidates, and between 53 and $73 \%$ of the Swedish candidates overestimated their driving skills. For these samples, the authors reported that the gender differences were too small (as indicated by the effect size) "to have any practical significance". In another study, student drivers tended to overestimate their own driving skills compared to their driving instructors' assessments (Victoir et al., 2005); however, the students' driving progress during training was not controlled in the analysis.

To our knowledge, no research has been conducted on the time course of drivers' self-assessments during driver training or on the impact of training variables (e.g., driving-lesson frequency or the number of instructor changes during the training, among other variables) on this time course. As a result, the present study examined the time course of student drivers' self-assessments during their initial driver training course. We measured students' selfassessments in relation to their general driving abilities using our French adaptation of Victoir et al.'s (2005) self-efficacy scale. Secondly, we examined the links between the self-ratings and the number of driving hours the learners estimate they still need before taking the driving test, considering this estimate as a kind of driving skills' development level self-assessed. In France, learning to drive is split into four steps (DSCR, 2005²): control the car at low or moderate speeds, with little or no traffic (Step 1), choose the car's position on the road and cross an intersection or turn (Step 2), travel under normal traffic conditions on roads or in built-up areas (Step3), and know all situations with particular difficulties (Step 4). We used these steps as references in the learners' driving skills development.

\footnotetext{
2 Road Safety Department, French Ministry of Transport.
}

In the present study, we set four goals: (1) to examine the psychometric qualities of our self-assessment scale, (2) to study the time course of the students' self-assessments, (3) to investigate the relationship between this time course and the number of driving hours the students estimate they still need before taking the driving test, and (4) to compare this number of hours to the number estimated by their driving instructors.

\section{Method}

The present study took place at 13 driving schools in Paris. It was carried out using a questionnaire and was presented to the driving schools and students as a survey aimed at better understanding students' judgments of their own driving. Each driving-school director allowed us to pass out the questionnaires in the school. Students and instructors were assured that their answers would remain strictly confidential and anonymous. The students and instructors were all volunteers and received no compensation for their participation in the study.

\subsection{Participants}

The participants included 150 students ( 58 men and 92 women) who reported that they had never driven a car before enrolling in driving school and 38 professional driving instructors. The 150 students were divided into four groups according to how far along they were in the four steps of the French driver training. Students ranged from 17- to 30 year olds, with a mean age of $22.2(S D=2.8)$, and they had an average of $30.2 \mathrm{~h}$ of practice driving $(S D=18.2$; Min. $=1 \mathrm{~h} ;$ Max. $=79 \mathrm{~h}$ ). As expected, the farther along the students were in the training, the higher the number of mean driving hours that they had completed (Table 1 ).

In this sample $(N=150), 62 \%$ of the students were monitored by several instructors: $34 \%$ had two instructors, $25 \%$ had three instructors, $2 \%$ had four instructors, and $1 \%$ had five instructors. Among the students who had several instructors $(N=94), 36 \%$ had one instructor change during the training, and $26 \%$ had regular instructor changes. For driving-lesson frequency $(N=150), 84 \%$ of the students drove an average of 2 to $4 \mathrm{~h}$ per week, $9 \%$ drove for more than $4 \mathrm{~h}$, and $6 \%$ drove for $1 \mathrm{~h}$ or less.

\subsection{Procedure}

Two versions of the questionnaire were generated: one for students and one for the instructors. Both groups were asked to fill out one of the two questionnaire versions at the end of a driving lesson. Filling out the questionnaire took about $10 \mathrm{~min}$.

\subsection{Questionnaire}

The questionnaire for the students had three parts. The first part measured the students' self-assessments of their driving with our French adaptation of Victoir et al.'s (2005) self-efficacy scale. The instructions for answering this scale were: Some people think that learning to drive a car is not easy. On the other hand, others think it's easy. How would you describe your current skills as a driver? The scale was composed of 12 items (see Table 2) with a 7-point Likert scale ranging from 1 (certainly so) to 7 (certainly not). Items 10 , 11 , and 12 were recoded before the analysis to be congruent with the general positive direction of the scale on the other items. When students checked the value 7 of the Likert scale, it was recoded as 1. Therefore, the Likert scale values were reversed for items 10, 11, and 12. The second part measured the number of driving hours the students estimated they still needed before taking the driving test. The third part collected socio-demographic data (gender and age). 
Table 1

Number of students and mean and standard deviation of driving hours by gender and training step.

\begin{tabular}{|c|c|c|c|c|c|c|c|c|c|c|c|c|}
\hline \multirow[t]{3}{*}{ Gender } & \multicolumn{12}{|c|}{ French driver training steps } \\
\hline & \multicolumn{3}{|c|}{ Step 1} & \multicolumn{3}{|c|}{ Step 2} & \multicolumn{3}{|c|}{ Step 3} & \multicolumn{3}{|c|}{ Step 4} \\
\hline & $N$ & $M$ & $S D$ & $N$ & $M$ & $S D$ & $N$ & $M$ & $S D$ & $N$ & $M$ & $S D$ \\
\hline Male & 11 & 8.4 & 6 & 25 & 24.3 & 12 & 12 & 41.1 & 14.7 & 10 & 41.3 & 13.8 \\
\hline Female & 24 & 11.6 & 8.4 & 29 & 29.6 & 14.4 & 22 & 41.1 & 15.4 & 17 & 51.8 & 18.1 \\
\hline
\end{tabular}

Table 2

Mean and standard deviation of students' self-ratings for each item of the selfassessment scale.

\begin{tabular}{lll}
\hline $\begin{array}{l}\text { Driving general self-efficacy scale } \\
\text { items }\end{array}$ & $M$ & $S D$ \\
\hline $\begin{array}{l}\text { 1. Driving a car is easy } \\
\text { 2. I have got my car under control }\end{array}$ & 3.85 & 1.47 \\
$\begin{array}{l}\text { 3. I am able to comply with traffic } \\
\text { rules }\end{array}$ & 4.29 & 1.33 \\
4. I drive well enough to pass the & 5.07 & 1.33 \\
exam & 3.67 & 1.74 \\
$\begin{array}{l}\text { 5. I am good in estimating risks in } \\
\text { traffic }\end{array}$ & 4.60 & 1.45 \\
6. I am good in foreseeing & & \\
dangerous situations & 4.23 & 1.35 \\
$\begin{array}{l}\text { 7. I can adapt my driving style to } \\
\text { environmental demands }\end{array}$ & 4.63 & 1.34 \\
8. I am good in manoeuvring the & & \\
car & 4.83 & 1.33 \\
$\begin{array}{l}\text { 9. I am sure of me when I drive a } \\
\text { car }\end{array}$ & & \\
10. I need more driving lessons & 4.37 & 1.43 \\
11. I find it hard to drive safely & & \\
12. I make driving errors & 2.74 & 1.80 \\
\hline
\end{tabular}

The questionnaire for the instructors had two parts: the first part assessed the number of driving hours the instructors estimated the students still needed before taking the driving test. In line with Groeger and Clegg (2007), we took this estimate as an indicator of the students' actual driving skills. The estimated number of driving-lesson hours given by the instructors was a kind of distance between the students' current level and the level needed to pass the test. For the second part, the driving-school files were used to col- lect several variables about the training of each students: number of driving hours, number of instructors, instructor changes during the training (no change, one change, and regular changes), and mean driving frequency in hours per week $(\leq 1 \mathrm{~h}, 2 \mathrm{~h}, 3 \mathrm{~h}, 4 \mathrm{~h}$, and $>4 \mathrm{~h}$ ). For cases in which students were trained by several instructors, there were two kinds of instructor changes during the training. "One change" meant that the students had two instructors and that there was one change of the instructor during the training; "regular changes" meant that the students had several instructors (2 or more) with several changes during the training (depending on the instructor and student availabilities).

\section{Results}

\subsection{French adaptation of the self-assessment scale}

\subsubsection{Psychometric qualities}

All in all, the learners rated their driving skills quite positively $(M=4.18, S D=1$, Min. = 2, Max. = 7). Items 10 and 12 obtained with lower averages, and item 3 got the highest average. The internal consistency of the driving questionnaire, measured by Cronbach's alpha, was satisfactory $(\alpha=.88$, Table 2$)$.

\subsubsection{Student self-assessment by number of instructors and changes, and by driving-lesson frequency}

The students were divided into three groups based on their mean scores on the self-assessment scale (negative $=[1 ; 3.5]$, average $=] 3.5$; 4.5], or positive $=14.5$; 7], Table 3 ). A greater number of students assessed themselves positively $(14.5 ; 7])$ when monitored by several instructors. The ratings were even more positive

Table 3

Percentages of student drivers who self-rated negatively, averagely and positively by driving training step, gender, instructor changes, and driving-lesson frequency.

\begin{tabular}{|c|c|c|c|c|}
\hline \multirow[t]{2}{*}{ Independent variables } & \multicolumn{3}{|c|}{ Measured variable: self-assessment } & \multirow[t]{2}{*}{$\chi^{2}$ test } \\
\hline & Negative $[1 ; 3.5]$ & Average]3.5; 4.5] & Positive]4.5; 7] & \\
\hline Driver training steps & & & & $\chi_{(6)}^{2}=29.15^{* * *}$ \\
\hline Step $1(n=35)$ & 48.57 & 40 & 11.43 & \\
\hline Step $2(n=56)$ & 24.07 & 40.74 & 35.19 & \\
\hline Step $3(n=34)$ & 5.88 & 44.12 & 50 & \\
\hline Step $4(n=27)$ & 7.41 & 33.33 & 59.26 & \\
\hline Gender & & & & $\chi_{(2)}^{2}=15.11^{* * *}$ \\
\hline Male $(n=58)$ & 10.34 & 34.48 & 55.17 & \\
\hline Female $(n=92$ & 30.43 & 43.48 & 26.09 & \\
\hline \multicolumn{5}{|l|}{ Instructors } \\
\hline Only one $(n=56)$ & 44.12 & 46.67 & 23.21 & $\chi_{(2)}^{2}=7.62^{*}$ \\
\hline Several $(n=94)$ & 55.88 & 53.33 & 76.79 & \\
\hline Instructor changes & & & & $\chi_{(4)}^{2}=14.05^{* *}$ \\
\hline No change $(n=56)$ & 26.79 & 50 & 23.21 & \\
\hline One change $(n=53)$ & 30.19 & 28.3 & 41.51 & \\
\hline Regular changes $(n=39)$ & 7.63 & 41.03 & 51.28 & \\
\hline Driving-lesson frequency (in h per week) & & & & $\chi_{(8)}^{2}=6.67$ \\
\hline$\leq 1(n=10)$ & 30 & 40 & 30 & \\
\hline $2(n=49)$ & 24.49 & 48.98 & 26.53 & \\
\hline $3(n=33)$ & 24.24 & 27.27 & 48.48 & \\
\hline $4(n=44)$ & 20.45 & 40.91 & 38.64 & \\
\hline$>4(n=14)$ & 14.29 & 35.71 & 50 & \\
\hline
\end{tabular}

${ }^{*} p<.05$.

*** $p<.01$.

*** $p<.001$. 
Table 4

Students' percentage by training step and instructor change(s).

\begin{tabular}{|c|c|c|c|c|}
\hline \multirow[t]{2}{*}{ Driver training steps } & \multicolumn{3}{|c|}{ Instructors changes } & \multirow{2}{*}{$\frac{\chi^{2} \text { test }}{\chi^{2}(6)=26,34^{* * *}}$} \\
\hline & No change & One change & $\begin{array}{l}\text { Regularly } \\
\text { changes }\end{array}$ & \\
\hline Step 1 & 37.5 & 18.9 & 10.3 & \\
\hline Step 2 & 35.7 & 45.3 & 25.6 & \\
\hline Step 3 & 10.7 & 17 & 48.7 & \\
\hline Step 4 & 16.1 & 18.9 & 15.4 & \\
\hline $\begin{array}{l}*{ }^{*} p<.05 \\
*_{* * *} \\
p<.01 \\
p<.001\end{array}$ & & & & \\
\hline
\end{tabular}

when they were regular instructor changes. However, lesson frequency did not influence the students' self-assessments. Next, we examined the links between instructor changes, training steps, and number of completed driving hours.

The students who did not change instructors were predominantly in Steps 1 and 2 of the training, whereas those who changed once were mainly in Step 2, and those who changed regularly were in Step 3 (Table 4). Thus, students who did not change instructors had completed fewer driving hours than those who had changed once $(p<.001)$. The students who changed instructors once had fewer completed driving hours than those who changed instructors regularly $\left(p=.05, F(2,145)=19.28, p<.001, \eta^{2}=.21, \omega^{2}=.99\right.$, Table 5).

\subsection{Students' self-assessments by gender and training step}

To examine the time course of the students' self-assessments during the training, a two-way ANCOVA was conducted: 2 (gender: male vs. female) X 4 (training step: S1 vs. S2 vs. S3 vs. S4) as between-group factors. Since learner age, instructor changes and total number of driving hours taken by the students could impact the self-assessments, these three variables were input into the analyses as covariates. The statistical significance level was set at .05, and the relative effect size was measured by $\eta^{2}$. Confidence in the effect size was measured by $\omega^{2}$. Significant effects were further examined using Tuckey's HSD Test for different $N$.

The main effect of gender was significant $(F(1,137)=10.29$, $\left.p<.001, \eta^{2}=.07, \omega^{2}=.88\right)$ : women's ratings were less positive $(M=3.9, S D=.99)$ than men's $(M=4.5, S D=.92)$. The main effect of training step was also significant $\left(F(3,137)=4.78, p<.001, \eta^{2}=.10\right.$, $\left.\omega^{2}=.99\right)$ : students in Step $1(M=3.45, S D=.92)$ gave themselves less positive ratings than those in Step $2(M=4.11, S D=.90, p<.001)$, in Step $3(M=4.56, S D=.79, p<.001)$ or in Step $4(M=4.80, S D=.97$, $p<.001)$. The ratings of students in Step 2 were less positive than of those in Step $4(p<.02)$, and the ratings of Step 3 students did not differ significantly from those of Step 4 students $(p>.05)$. The interaction between gender and training step was not statistically significant $\left(F(3,137)=.62, p=.61, \eta^{2}=.01, \omega^{2}=.18\right.$, Fig. 1$)$. This effect was exactly in line with the main effect of training step for both the male and female students. Furthermore, in each step, the male students' self-ratings did not differ significantly from those of the female students. Thus, globally the male students were selfassessed more positively than the woman students, but there was no significant difference in the same training step. The covariates were not significant: age $\left(F(1,137)=.19, p=.67, \eta^{2}=.00, \omega^{2}=.07\right)$,

Table 5

Number of students' driving hours by instructor change(s).

\begin{tabular}{|c|c|c|c|c|c|c|c|c|}
\hline \multicolumn{9}{|c|}{ Instructor changes } \\
\hline \multicolumn{3}{|c|}{ No change } & \multicolumn{3}{|c|}{ One change } & \multicolumn{3}{|c|}{ Regular changes } \\
\hline$N$ & $M$ & $S D$ & $N$ & $M$ & $S D$ & $N$ & $M$ & $S D$ \\
\hline 56 & 19.8 & 16 & 53 & 32 & 17.9 & 39 & 40.8 & 15.2 \\
\hline
\end{tabular}

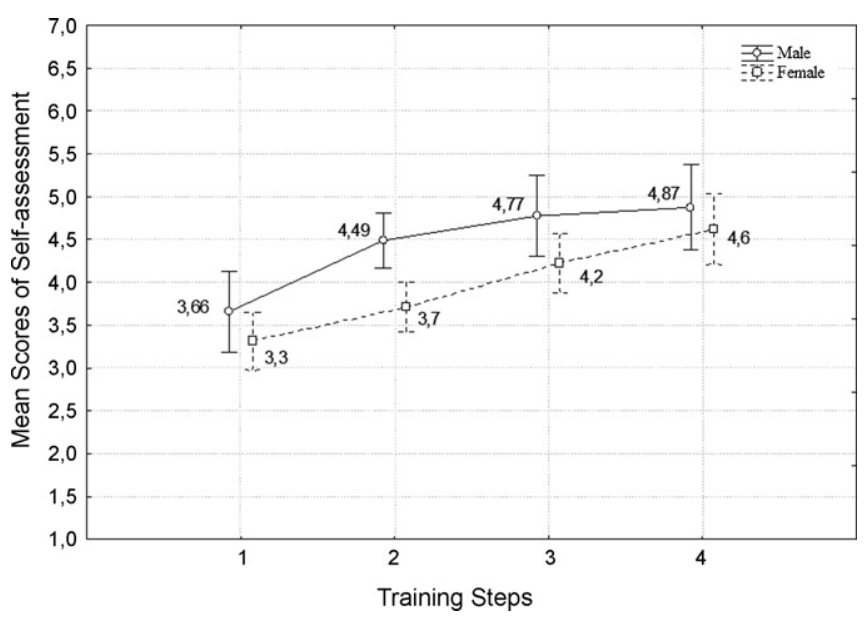

Fig. 1. Students' mean self-assessment ratings during driver training by gender.

instructor changes $\left(F(1,137)=2.16, p=.14, \eta^{2}=.02, \omega^{2}=.31\right)$, and total number of driving hours taken by the students $(F(1,137)=.31$, $\left.p=.58, \eta^{2}=.00, \omega^{2}=.09\right)$.

\subsection{Links between students' self-assessments and the number of driving hours estimated by students and instructors}

\subsubsection{Correlation analysis}

The difference between the students' and the instructors' estimates of the number of driving-lesson hours the students still needed before taking the driving test was determined by subtracting the instructors' estimates from the students' estimates. When the difference was positive, it indicated that the student overestimated the number of hours needed before taking the test.

Globally, the students' self-ratings of their driving skills were negatively correlated with their estimates of the number of drivinglesson hours before taking the test $(p<.001)$ and the instructors' estimates $(p<.01)$ Furthermore, the self-ratings were positively correlated with the instructor changes $(p<.001)$ and the total number of hours taken by the students $(p<.01)$. However, the selfratings were not correlated with the estimation difference between the students and the instructors. In addition, the students' estimates were positively correlated with the instructors' estimates (Table 6, $p<.001$ ).

\section{Table 6}

Correlation matrix: self-ratings, instructors changes, total number of hours taken by students, number of hours needed before taking the test estimated by students and by instructors and, estimation difference between the students and the instructors.

\begin{tabular}{|c|c|c|c|c|c|c|}
\hline Variables & 1 & 2 & 3 & 4 & 5 & 6 \\
\hline Self-rating (1) & 1 & & & & & \\
\hline Instructor changes (2) & $.35^{* * *}$ & 1 & & & & \\
\hline $\begin{array}{l}\text { Total number of hours } \\
\text { taken by students ( } 3 \text { ) }\end{array}$ & $.25^{* *}$ & $.46^{* * *}$ & 1 & & & \\
\hline $\begin{array}{l}\text { Number of hours } \\
\text { needed before taking } \\
\text { the test estimated by } \\
\text { students ( } 4 \text { ) }\end{array}$ & $-.33^{* * *}$ & $-.25^{* *}$ & -.04 & 1 & & \\
\hline $\begin{array}{l}\text { Number of hours } \\
\text { needed before taking } \\
\text { the test estimated by } \\
\text { instructors (5) }\end{array}$ & $-.25^{* *}$ & $.40^{* * *}$ & $.22^{* *}$ & $.31^{* * *}$ & 1 & \\
\hline $\begin{array}{l}\text { Estimation difference } \\
\text { between the students } \\
\text { and the instructors ( } 6 \text { ) }\end{array}$ & -.08 & .11 & .15 & $.62^{* * *}$ & $-.55^{* * *}$ & 1 \\
\hline
\end{tabular}




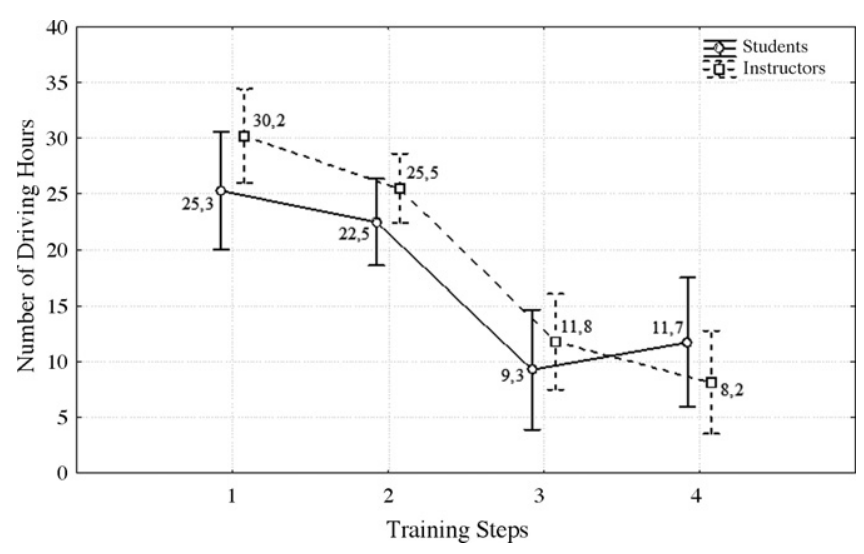

Fig. 2. Number of driving hours estimated by students and instructors by training step. Vertical bars indicate confidence intervals at .95 .

The learners' estimates seemed to be rather in line with the instructors' estimates and link with the time course of the selfratings. However, the self-ratings would not link with the accuracy of the students' estimates. In contrast, the training variables (instructor changes and total number of hours taken by students) seemed to be involving the time course of the self-ratings.

\subsubsection{ANCOVA on the number of driving hours estimated by the students and instructors}

To compare students' and the instructors' estimates of the number of hours that the students needed before taking the driving test, a repeated-measures ANCOVA was conducted using a mixed design: 2 (gender: men vs. women) $\times 4$ (training step: S1 vs. S2 vs. S3 vs. S4) as between-group factors, $\times 2$ (estimate source: student vs. instructor) as within-group factor. Age, instructor changes, and total number of driving hours taken by the students were input into the analysis as covariates.

The main effect of training step was significant $(F(3,137)=17.94$, $\left.p<.001, \eta^{2}=.28, \omega^{2}=1\right)$ : students' and instructors' estimates of the number of remaining hours decreased as the students progressed in the training (Fig. 2). However, these estimates did not differ significantly, whether between training Steps 1 and $2\left(M_{1}=28.5, S D_{1}=12.8 ; M_{2}=23.5, S D_{2}=15.1 ; p=.12\right)$ or between Steps 3 and $4\left(M_{3}=11.3, S D_{3}=8.1 ; M_{4}=7.1, S D_{4}=1.2 ; p=.87\right)$. In contrast, these estimates were significantly higher for Steps 1 and 2 students as compared to Step 3 and 4 students ( $p s<.001$ ). The main effect of gender was not significant, nor was the estimate source $(F s<1)$. Thus, the students' estimates did not significantly differ from the instructors' estimates. The interactions were not significant $(F s<1)$. Therefore, the students were reasonably accurate in estimating the number of driving lessons still needed since the beginning of the driver training. The covariates were not significant: age $\left(F(1,137)=.03, p=.87, \eta^{2}=.00, \omega^{2}=.05\right)$, instructor changes $\left(F(1,137)=.09, p=.75, \eta^{2}=.00, \omega^{2}=.06\right)$, and total number of driving hours taken by the students $(F(1,137)=.41, p=.51$, $\left.\eta^{2}=.00, \omega^{2}=.06\right)$.

\section{Discussion}

One way to improve the road safety for young drivers would be to foster students' self-assessment accuracy during their initial driving training (Hatakka et al., 2002; MERIT, 2005). However, it seems essential to first examine the time course of student drivers' assessments of their own driving skills. Because not much is known about the development of these assessments, the present study was aimed at shedding light on this issue using our French adaptation of Victoir et al.'s (2005) self-efficacy scale.
The French version of this scale presented satisfactory psychometrics qualities. This scale had a good internal consistency level $(\alpha=.88)$ and was sensitive to the influence of both internal (i.e. gender) and external factors (i.e. training step) on the students' assessments of their own driving skills.

The students' self-assessments became more positive as they progressed through the training (at the beginning of the training, $M=3.45$ vs. at the end of the training, $M=4.8$ ). Thus, the more skills that they acquired during the training, the more positively they assessed their driving skills. This finding is in agreement with the results of Bandura's research (1997) on self-efficacy and with Spolander's (1983) study, which showed that drivers assessed themselves as more skillful with increasing experience. Furthermore, men rated globally their driving skills more positively compared to women, but the effect size was too small "to have any practical significance", which is in agreement with previous studies (Mynttinen et al., 2009a, 2009b). In addition, no significant difference was observed between the men and the women at each training step. In contrast, these last results were not in agreement with the gender difference that has been observed in experienced drivers (Delhomme, 1991; OECD, 2006) and in novice drivers (Gregersen, 1996; Delhomme and Meyer, 2004; Katila et al., 2004).

Several other driver training's variables also had an impact on the students' self-assessments. The number of instructors and of instructor changes during the training affected the students' selfratings, whereas the driving-lesson frequency did not have an effect. A greater number of students rated themselves positively when monitored by several instructors with regular changes (i.e. several instructor changes during the training). However, students monitored by several instructors with regular changes were more advanced in the driver training; therefore, we could not separate the effect of the student level and the effect of instructor changes on the students' self-assessments in this study. However, Vidal-Gomel et al. (Vidal-Gomel and Rogalski, 2007; Vidal-Gomel et al., 2009) demonstrated that regular changes in instructors could disorganize the driving lessons. This finding may explain why students needed a larger number of driving hours in the same training step when they had several instructor changes. However, this explanation needs to be confirmed by further studies.

In general, the more advanced the students were, the better their ratings of their own driving skills and the lower the number of driving-lesson hours they felt they needed before taking the driving test (as indicated by correlations). Thus, the self-assessments would involve the students' estimates. Otherwise, the number of hours estimated by the students did not differ significantly from that estimated by the instructors throughout the training steps. The students (men and women) were rather accurate in estimating the number of driving lessons still needed. Therefore, we did not observe a development of this accuracy by the students. Furthermore, the self-assessments seemed not to be related to the accuracy of the students' estimates.

However, taking the instructors' estimates of the number of hours that the students needed before taking the driving test as an indicator of the students' actual driving skills, the students' selfassessments seemed to be in agreement with their current skills in relation to their driving in general. Therefore, the student drivers seemed to have made "realistic" self-assessments of their driving skills. These results do not agree with previous findings, such as those reported by Victoir et al. (2005) about students' self-ratings and by Mynttinen et al. (2009a, 2009b) about driving-test candidates' self-assessments. It would have been fruitful to compare the instructors' and the students' estimates to the number of drivinglesson hours that the students completed before taking the driving test. However, when we re-contacted the driving schools, we could not collect these data because most of the students' training files had not been stored in a numeric format. 
In conclusion, the students' self-assessments became more positive during the initial driver training as it was observed here in relation to their driving in general. Furthermore, the time course of the self-ratings was affected by some training variables. These results need to be confirmed by further studies, but its question the relationship between the pedagogical choices and the work organization of the driving schools, and the skills development process during driver training. The accuracy of the self-assessments' was not the purpose of this study; however, according to Bandura (1997), self-efficacy is a key dimension in preparing drivers to cope with the requirements of the driving situations. Thus, the present findings provide sufficient incentive to focus future research on the time course of students' self-assessments and the development of the accuracy of self-assessments. For example, it would be useful to examine the students' self-ratings in relation to situations that are risky for all drivers and especially for young, novice drivers, such as turning at an intersection (especially, turning left with cross-flow) (Clarke et al., 1998a, 1999a, 2005a), overtaking (Clarke et al., 1998b, 1999b), and driving on country roads (Clarke et al., 2005b).

\section{References}

Baldock, M., Mathias, J., Mclean, A., Berndt, A., 2006. Self-regulation of driving and its relationship to driving skill among older adults. Accident Analysis \& Prevention 38 (5), 1038-1045.

Ball, K., Owsley, C., Stalvey, B., Roenker, D.L., Sloane, M.E., Graves, M., 1998. Driving avoidance and functional impairment in older drivers. Accident Analysis \& Prevention 30 (3), 313-322.

Bandura, A., 1997. Self-Efficacy. The Exercice of Control.W.H. Freeman and Company, New York.

Clarke, D.D., Forsyth, R., Wright, R., 1998a. Behavioural factors in accidents at road junctions: the use of a genetic algorithm to extract descriptive rules from police case files. Accident Analysis \& Prevention 30 (2), 223-234.

Clarke, D.D., Forsyth, R., Wright, R., 1999a. Junction road accidents during cross-flow turns: a sequence analysis of police case files. Accident Analysis \& Prevention 31 (1-2), 31-43.

Clarke, D.D., Forsyth, R., Wright, R., 2005a. A statistical profile of road accidents during cross-flow turns. Accident Analysis \& Prevention 37 (4), 721-730.

Clarke, D.D., Ward, P., Truman, W., 2005b. Voluntary risk taking and skill deficits in young driver accidents in the UK. Accident Analysis \& Prevention 37 (3), 523-529.

Clarke, D.D., Ward, P.J., Jones, J., 1998b. Overtaking road-accidents: differences in manoeuvre as a function of driver age. Accident Analysis \& Prevention 30 (4), $455-467$.

Clarke, D.D., Ward, P.J., Jones, J., 1999b. Processes and countermeasures in overtaking road accidents. Ergonomics 42, 846-867.

Delhomme, P., 1991. Comparing one's driving with others': assessment of abilities and frequency of offences. Evidence for a superior conformity of self-bias? Accident Analysis \& Prevention 23 (6), 493-508.

Delhomme, P., Meyer, T., 2004. Risk taking and self-efficacy among young male driver: self-efficacy and changing task demands. Traffic and Transport Psychology, 135-145.

Dscr, 2005. Le livret d'apprentissage. Véhicules légers. Guide technique de sécurité routière, La documentation française, Paris.

Eby, D.W., Molnar, L.J., Shope, J.T., Vivoda, J.M., Fordyce, T.A., 2003. Improving older driver knowledge and self-awareness through self-assessment: the driving decisions workbook. Journal of Safety Research 34 (4), 371-381.
Engström, I., Gregersen, N.P., Hernetkoski, K., Keskinen, E., Nyberg, A., 2003. Jeunes conducteurs novices, éducation et formation du conducteur. Institut National Suédois de Recherche sur les Routes et les Transports, Linköping, Suède.

Freund, B., Colgrove, L.A., Burke, B.L., Mcleod, R., 2005. Self-rated driving performance among elderly drivers referred for driving evaluation. Accident Analysis \& Prevention 37 (4), 613-618.

Gregersen, N.P., 1996. Young drivers' overestimation of their own skill - an experiment on the relation between training strategy and skill. Accident Analysis \& Prevention 28 (2), 243-250.

Groeger, J.A., 2000. Understanding Driving: Applying Cognitive Psychology to A Complex Everyday Task. Psychology Press, Hove.

Groeger, J.A., Clegg, B.A., 2007. Systematic changes in the rate of instruction during driver training. Applied Cognitive Psychology 21 (9), 1222-1244.

Hatakka, M., Keskinen, E., Gregersen, N.P., Glad, A., Hernetkoski, K., 2002. From control of the vehicle to personal self-control: broadening the perspectives to driver education. Transportation Research Part F 5, 201-215.

Katila, A., Keskinen, E., Hatakka, M., Laapotti, S., 2004. Does increased confidence among novice drivers imply a decrease in safety?: the effects of skid training on slippery road accidents. Accident Analysis \& Prevention 36 (4), 543-550.

Lajunen, T., Summala, H., 1995. Driving experience, personality, and skill and safety-motive dimensions in drivers' self-assessments. Personality and Individual Differences 19 (3), 307-318.

Lyman Jr., J.M.G.M., Sims, R.V., 2001. Factors related to driving difficulty and habits in older drivers. Accident Analysis \& Prevention 33, 413-421.

Marottoli, R.A., Richardson, E.D., 1998. Confidence in, and self-rating of, driving skill among older drivers. Accident Analysis \& Prevention 30 (3), 331-336.

Matthews, M., 1986. Aging and the perception of driving risk and skill. In: Proceedings of the Human Factors Society 30th Annual Meeting, pp. 1159-1163.

Maycock, G., 2002. Novice Driver Accidents and the Driving Test. TRL Report No. 527. Transport Research Laboratory, Crowthorne, UK.

Mckenna, F.P., 1993. It won't happen to me: unrealistic optimism or illusion of control? British Journal of Psychology 23, 45-52.

Minimum Requirement for Driving Instructor Training (Merit), 2005. European Project. Institute Gute Fahrt, Vienna.

Mynttinen, S., Sundström, A., Koivukoski, M., Hakuli, K., Keskinen, E., Henriksson, W., 2009a. Are novice drivers overconfident? A comparison of self-assessed and examiner-assessed driver competences in a Finnish and Swedish sample. Transportation Research Part F 12 (2), 120-130.

Mynttinen, S., Sundström, A., Vissers, J., Koivukoski, M., Hakuli, K., Keskinen, E. 2009b. Self-assessed driver competence among novice drivers - a comparison of driving test candidate assessments and examiner assessments in a Dutch and Finnish sample. Journal of Safety Research 40 (4), 301-309.

Organisation for Economic Co-operation and Development, 2001. Vieillissement et transports. Concilier mobilité et sécurité. Transports. OCDE.

Organisation for Economic Co-operation and Development, 2006. Jeunes conducteurs: La voie de la sécurité OCDE/CEMT.

Siegrist, S., 1999. Driver Training, Testing and Licensing - Towards Theory-Based Management of Young Drivers' Injuries Risk in Road Traffic. Results EU-project GADGET. BFU, Berne.

Spolander, K., 1983. Drivers' Assessment of Their Own Driving Ability. Report No. 252. Swedish Road and Traffic Research Institute, Linköping.

Stalvey, B.T., Owsley, C., 2000. Self-perceptions and current practices of high-risk older drivers: implications for driver safety interventions. Journal of Health Psychology 5, 441-456.

Sundström, A., 2008. Self-assessment of driving skill - a review from a measurement perspective. Transportation Research Part F 11 (1), 1-9.

Victoir, A., Eertmans, A., Bergh, O.V.D., Broucke, S.V.D., 2005. Learning to drive safely: social-cognitive responses are predictive of performance rated by novice drivers and their instructors. Transportation Research Part F 8, 59-74.

Vidal-Gomel, C., Boccara, V., Rogalski, J., Delhomme, P., 2009. When drivers' trainingcourses are shared by different instructors. In: Proceedings of the 17th World Congress Ergonomics, 7-14 Augustm, Peking, China, CD-Rom.

Vidal-Gomel, C., Rogalski, J., 2007. Driver training: the collective dimension in trainers' activity. In: Proceedings of the ECCE, London. 